\title{
Seamless Learning Model with Enhanced Web-Quizzing in the Higher Education Setting
}

\author{
https://doi.org/10.3991/ijim.v16i03.27257 \\ Svitlana Mykytiuk ${ }^{1(\bowtie)}$, Tetiana Moroz ${ }^{1}$, Serhii Mykytiuk², \\ Mykola Moroz ${ }^{1}$, Olga Dolgusheva ${ }^{3}$ \\ ${ }^{1}$ Yaroslav Mudryi National Law University, Kharkiv, Ukraine \\ ${ }^{2}$ Department of Philosophical and Psychological Anthropology, \\ H.S. Skovoroda Kharkiv National Pedagogical University, Kharkiv, Ukraine \\ ${ }^{3}$ Department of Germanic Languages and Teaching Methodology, Volodymyr Vynnychenko \\ Central Ukrainian State Pedagogical University, Kropyvnytskyi, Ukraine \\ s.s.mykytyuk@nlu.edu.ua
}

\begin{abstract}
The research studied the effectiveness of a three-stage Seamless Learning Model with Enhanced Web-Quizzing based on the intensive use of sets of quizzes created in different web-based quiz generators. The findings revealed that continuous testing using diagnostic, formative, benchmark and summative quizzes, administered at the three stages - familiarisation, formation and assessment, applying such features of seamless learning as learning in various contexts, ubiquitous access to digital learning resources and quizzes, combination of teacher-guided learning, self-directed and collaborative learning, and switching between various learning activities can be an efficient teaching technique in higher education having positive effect on academic performance, motivation, learners' approaches to studying and course engagement. The testing effect was investigated on the summative tests taken at the end of the three different academic courses. The results showed that online quizzes applied primarily as learning tools with the emphasis on information retrieval and retention resulted in the higher achievements of the experimental group students. The survey conducted with Biggs's Revised Two-Factor Study Process Questionnaire (R-SPQ-2F) showed the changes in the learners' motives and approaches to studying revealed in students' active participation in in-class and out-of-class activities, mastering of the material through understanding rather than mechanical memorizing, the search for additional information and increased attendance. The engagement of the experimental group students in the new quiz-enhanced settings was examined focusing on emotional, skills, participation and performance engagement aspects.
\end{abstract}

Keywords—engagement, academic performance, seamless learning, testing effect, web quizzing

\section{Introduction}

The challenges that the world educational community faces in the pandemic time make us find an efficient methodology that will help to cope with the arisen difficulties and transform progressively the existing learning methods into the sustainable practice 
of seamless learning. In this vein, the potential of educational web quizzing tools has to be investigated and productively exploited. Higher educational institutions nowadays are experimenting with the employment of their opportunities, which can be of value from psychological, pedagogical and technical views.

The potential of web quizzing primarily is studied through the prism of general features of cloud computing. The importance of new common cloud computing services cannot be overestimated nowadays. In education, their value is supposed to grow to $\$ 25.36$ billion by 2021 , with an annual growth rate of over $25 \%$ [1]. The problem of harnessing the power of cloud computing for teaching purposes is widely studied nowadays [2]-[5], etc.

Besides the technical (access at the fingertips, minimal hardware requirements, large data-storage capacity, fast processing of information), economic (cost-effectiveness) and sustainability (energy efficiency and reduction in computer-related emissions) reasons, special attention is paid to the ability of these services to change the nature of the learning environment. Firstly, cloud-based computing advancements make it innovative and technologically forward. It leads to the fact that students not only get acquainted with new interfaces, but they also acquire both real-life and career-important skills significant in this technological age. Secondly, accessibility to learning resources makes the studying process mobile and flexible, which improves students' study-life balance. Thirdly, the learning becomes collaborative as communication and sharing of information become simple in new virtual communities. Fourthly, cloudbased platforms provide abilities to create a personalized learning environment making education student-centred.

The purpose of the research was to investigate the academic potential of enhanced web quizzing for seamless learning in the higher educational setting. The objectives of the study were:

- to analyse the existing theoretical underpinnings of seamless learning and testing effect;

- to determine the impact of the suggested Seamless Learning Model with Enhanced Web-Quizzing on students' learning of the target content and to check statistically students' progress in the final test performance;

- to analyse the influence of the new methodology on academic motivation and approaches to the studying process;

- to evaluate students' engagement in the quiz-enhanced courses.

\section{Literature review}

\subsection{Seminal principles of seamless learning}

Seamless learning is understood as a learning approach "when a person experiences a continuity of learning, and consciously bridges the multi-faceted learning efforts, across a combination of locations, times, technologies or social settings [6].

The notion of seamless learning was introduced in 1990s in the research of higher education transformation that presupposed the linking of different learning experiences 
that used to be distinct parts (in-class and out-of-class, curricular and co-curricular, or on-campus and off-campus) into one continuous process where students could benefit from learning resources existing both inside and outside of the classroom environment [7]. Later it was reshaped in the context of technology-enhanced learning [8] and studied as mobile-assisted seamless learning with the emphasis on implementation of technological innovations with the aim to create personalized learning practices across various contexts [9]. Seamless learning sometimes was viewed as synonymic to ubiquitous learning [10] which is based on mobile technology that promotes learning in different environments and anytime. Flexibility and quick access to necessary information are its basic features. Meanwhile, some researchers proved that seamless learning could be achieved in blended learning without mobile technology, for example, by combining live lectures and blogging on PC [11].

The studies of seamless learning from a curriculum design perspective helped to define the seams (gaps) in the educational setting that should be removed to support learners. For this reason, 10 dimensions of mobile-assisted seamless learning were distinguished: 1) encompassing formal and informal learning; 2) encompassing personalized and social learning; 3) across time; 4) across locations; 5) ubiquitous access to learning resources; 6) encompassing physical and digital worlds; 7) combined use of multiple device types; 8) seamless switching between multiple learning tasks; 9) knowledge synthesis; 10) encompassing multiple pedagogical and leaning activity models [9].

The following characteristics of seamless learning were also accentuated such as learner-centeredness as it allows students to take initiative, monitor progress, solve problems, etc.; ability to stimulate ongoing self- and co-construction of knowledge due to access to different learning resources and spaces [12]. Integrated and synergistic effects of learning in formal and informal contexts [13] are stressed which helps achieve more holistic notions of learning as students gain canonical knowledge about a subject or topic from the formal environment while in the informal one they experience this subject or topic in different natural contexts [14].

Recent research considers seamless learning as a set of meta-cognitive abilities, schematized and habitual regulatory strategies [15] that can promote life-long learning of a seamless learner. Various approaches to studying this phenomenon nowadays show its topicality in the digital age and its constantly developing nature.

\subsection{The testing effect phenomenon}

The phenomenon of testing effect sometimes called retrieval practice, practice testing, or test-enhanced learning is understood as the finding that taking a test leads to better retention than does restudying that material for the same period [16], [17]. Testing information presupposes information processing (analysis, synthesis, generalization, etc.) and information retrieval that activates different cognitive mechanisms, which powerfully impacts learning and long-term retention [18], [19].

Information retrieval is considered to be essential for information retention. In case a test is seen not only as an assessment tool but if it specially focuses on retrieval it broadens its nature. Testing can be a useful mnemonic device because the act of retrieving information from memory has a direct effect on the later retrievability of that 
information [19]. The constructive retrieval is studied that takes into account goals and expectations of the participant, test format and the mental model of the studied material and means constructive processes that strengthen the memory for the retrieved information and additionally initiate retrieval of the information associated with the target content [20]. The observation that the initially non-tested information can benefit from prior testing of related material [21] can be connected with this phenomenon.

Modern research distinguishes the backward testing effect that refers to the phenomenon that testing consolidates retention of studied information [8], [22], [23], [24], [25], etc. from the forward testing effect that facilitates learning of new information [26], [27]. Traditionally the presence of testing effect is examined by comparing the final learning achievements of two groups - in which test-enhanced learning was applied and in which other strategies were administered (restudying, no treatment, concept mapping, etc.) [8], [18], [19], [28], etc. Numerous explanations of the positive effect of this technique, which are sometimes overlapping, are suggested, among them, several most spread theories should be noted. Additional exposure theory suggests that learning and retention are enhanced by often exposure to the target material, testing with corrective feedback is more beneficial than without it [29]. The immediate feedback feature of quizzes is paid special attention as it shows the result immediately, helps to achieve the aim, increases learner engagement, and may promote student's autonomy in the educational process [29], [30]. Retrieval effort theory states that the more difficult tests, the more demanding retrieval processes that boost long-term memory [19], failure in prior tests motivates more efforts to retrieve target information in further tests [31]. Motivation theory claims that frequent testing motivates students to invest more effort to studying [27]. Expectancy of subsequent testing changes approaches to learning (better attendance [32], allocating more time to learning [27], better preparation before classes [33], etc.). The test achievement can lead to self-correction of learning strategies as test failure or success may improve students' metacognition [34], [35], which may eliminate 'the illusion of knowing' or 'illusions of competence' [36], [37]. Transfer-appropriate processing theory proposes that acquisition tests and final assessment tests require similar mental processes, thus testing is more beneficial when the test formats of the two stages are matched [38]. Some research shows that taking quizzes frequently can help reduce the anxiety that students may face during a test [28].

Consideration of these theoretical underpinnings in curricular development may become a significant strategy for successful teaching in the pandemic-altered educational setting.

The researchers hypothesize that the intensive use of web quizzing may be an efficacious educational technique for seamless learning. Firstly, the above-mentioned potential of different innovative cloud-based technologies can promote ubiquitous learning with multiple learning tasks in different settings. Secondly, the general testing effect may influence exam and final test performance and, thirdly, utilization of instructional strategies that can impact the inner motivational potential of learners may change students' learning strategies and boost motivation and engagement. This research appears to be a comprehensive study on the direct and indirect benefits of web quizzes and has a multi-disciplinary approach. 


\section{$3 \quad$ Methodology}

During the study, the researchers utilized analysis and synthesis as general research methods to investigate theoretical issues on seamless learning, testing effects, and specifics of cloud computing quizzes. In the course of our empirical study, the following methods have been applied: observation, interpretation, quasi-experiment and survey.

\subsection{Participants}

The research was carried out at the three educational establishments-Yaroslav Mudryi National Law University, H.S. Skovoroda Kharkiv National Pedagogical University and Volodymyr Vynnychenko Central Ukrainian State Pedagogical University - during the second semester of the 2019-2020 academic year. The participants were students studying for a bachelor's degree taking three different university courses: "English Language", "Civil Law", and "Child and Educational Psychology". The duration of each course was two semesters. All the students were informed about the nature of the research and participated voluntarily.

\subsection{Research material}

To carry out the research the authors designed a three-stage Seamless Learning Model with Enhanced Web-Quizzing in which cloud-based tests were divided into 3 main groups according to their purposes and places in the educational process. The test generators used to create quizzes were Edpuzzle, GoConqr, Kahoot!, Mentimeter, Microsoft forms, Pear Deck, Quizizz, Quizlet, Socrative, TeachVid, Vocabulary, etc. This variety helped to employ various test types and multimedia format materials to perform different functions and diversify the learning process. The links to the tests and the additional materials were provided on the Microsoft Teams platform.

At the first familiarisation stage, diagnostic tests were utilized. They were placed before each lesson and contained new information of upcoming lessons to boost students' interest in the target material; to make them find the information they do not know in any resources either provided by the teachers on Microsoft Teams (different course materials, presentations, lectures or any other videos or audios) or in any other available and accessible resources; to test students' prior knowledge on the topic, their understanding of the basic concepts. Students could take them in collaboration with peers; out-of-class tests were not time-limited. The value of diagnostic tests was not in the quantitative assessment of students' knowledge, but in providing facilitated and at the same time self-regulated seamless learning and tailoring further instructional strategies. Administering these tests researchers applied some principles of the flipped classroom model. The lower level of learning (according to Bloom's taxonomy) such as understanding and remembering in this way took place before the lesson through autonomous self-exploration learning. This approach resulted in the meaningful practice of the cognitive levels (applying and analysing) during the lesson when students familiar with the target material could more productively participate in discussions, explain 
notions, solve problems, etc. A typical diagnostic test consisted of 2 to 3 open-ended, 5 to 6 short-answer, or 6 to 10 multiple-choice or true-false questions.

The second formation stage used formative tests and benchmark tests. Formative tests were given during classes in an ongoing format or after them with the purpose to monitor students' learning progress, their understanding of the material under study, to identify weak points and to address them immediately by providing immediate feedback indicating which aspect they have to focus on. We considered that carefully arranged questions of the tests with obligatory repetitions could promote a deeper understanding of the topic and refining of course knowledge and skills. This encouraged more thorough knowledge construction and skills development. The application of different multimedia format tests was aimed at changing the modes of target-material practice and participation transformation.

Benchmark tests were placed at the end of a unit/module to gauge test-takers' knowledge of the studied material, provide tutors with periodic information about student progress. Results of the benchmark tests assisted to identify students' strengths and weaknesses and modify instructions and adjust the learning environment.

The third assessment stage employed summative tests that were taken by students at the end of the course as a final test in which they had to demonstrate their overall knowledge on the subject and acquired skills at a level prescribed at the programs.

\subsection{Instruments and research procedure}

The research was conducted in three main stages-pre-experimental stage, experimental teaching and experimental assessment.

During the pre-experimental stage, the sampling of participants was made. After the first semester according to the scores obtained at the final tests of the first semester, from 18 academic groups enrolled to the courses (8 groups - "English Language"; 6 groups - “Civil Law"; 4 groups - “Child and Educational Psychology") 6 academic groups ( 3 experimental and 3 control groups; in each course 1 experimental and 1 control group) showing approximately similar results were chosen for the research. The total number of participants was 129 persons - experimental group students $(\mathrm{N}=65)$ and control group students $(\mathrm{N}=64)$.

Experimental teaching included the teaching of the same course materials determined at the syllabi of the three academic disciplines to the students of the experimental and control groups. In the control groups, traditional teaching methods were applied while in the experimental groups a specially designed Seamless Learning Model with Enhanced Web-Quizzing described above created in different web-based quiz generators was utilized. The treatment with the new methodology was conducted during the four months of the second semester of the courses.

The researchers organized seamless learning as a continuous process that integrated the following aspects: 1) learning in various contexts-physical (in-class and home learning) contexts and virtual classrooms (all additional materials, quizzes or links to them where provided on the Microsoft Teams platform); each home task during the courses was obligatory accompanied by a quiz for experimental groups; 2) ubiquitous access to digital learning resources and quizzes (their cloud-based nature made them 
permanently available at any suitable time and place through any devices); 3) combination of teacher-guided learning (students received feedback on each quiz; quiz results helped alter the instructional strategies), self-directed learning (quizzes as home assignments could be taken at any time before the next lesson as soon as students felt ready and the 'open-book' approach was applied (learners were allowed to use any resources)) and collaborative learning (taking some tests students were divided in teams; home task tests could be discussed with peers); 4) mixture of formal and informal learning (additional materials for elective reading, various TV and radio units, podcasts were suggested, some of them were provided via the closed Facebook group for the English Language course); 5) switching between various learning activities (tests taken before lessons helped more productively organize practice of not only knowledge acquisition but also cognitive skills development).

Experimental assessment included several steps.

1. At the end of the semester, to ascertain the hypothesis that the intensive use of quizzes can influence the academic performance of students, final tests in three courses were administered. To check the presence of testing effect the questions of the tests included only in-class covered (in both control and experimental groups) and previously tested in experimental groups material (none of these questions were repeated as they were provided in previous tests). The achievements (scores obtained) of control and experimental group students on the final tests (scored max.100) were examined. The data was collected, analysed and interpreted based on descriptive statistics (mean, standard deviation) and inferential statistics (independent samples t-test) by means of SPSS. The comparison between the final test results obtained in control and experimental groups allowed us to check the productivity of the suggested methodology. The comparative analysis of the students' academic performance on different academic courses was presented graphically.

2. At the end of the courses after the final tests, to check the hypothesis that the enhanced use of tests can impact learning strategies and motivation the evaluation of the academic motivation and learners' approaches to their studying was conducted in both experimental and control groups. The used instrument was Biggs's Revised Two-Factor Study Process Questionnaire (R-SPQ-2F) [39] which validity and reliability were indicated in various research works [40], [41]. The administered questionnaire was focused on the study of two main approaches: deep approach (deep motivation and deep strategy) and surface approach (surface motivation and surface strategy). It contained 20 questions given in the cyclical order checking different approaches (1) deep motive, 2) deep strategy, 3) surface motive, 4) surface strategy, 5) ... etc.). Students provided their responses according to a 5-point Likert-type scale (from 'this item is never or only rarely true of me' to 'this item is always or almost always true of me'). The number of definite answers given by students in the online administered questionnaire revealed students' approaches. The collected data was organized, classified, tabulated, analysed and interpreted based on descriptive statistics (mean and standard deviation) using SPSS.

3. At the end of the courses, the researchers examined the engagement of the experimental group students $(\mathrm{N}=65)$ in the quiz-enhanced courses to ascertain the hypothesis that the experimental methodology can boost course engagement due to the 
innovative instructional strategies. The applied instrument was a specially designed by the authors of this research 5-point Likert scale questionnaire (from 'strongly disagree' to 'strongly agree') containing 9 statements that checked students' opinions on the four components: emotional engagement (emotional connection to the course material (1-3 statements)), skills engagement (general learning strategies (4-5)), participation engagement (willingness to participate and interact (6-7)) and performance engagement (impact on the achievement results (8-9)). According to the research by Handelsman et al. [42], they are reliable self-report indicators of student engagement in a course. Each of the four components is characterized by definite behaviours, attitudes or motivations related to the course content. They were reflected in the statements of the questionnaire. The engagement indicator is very important as it helps not only to understand self-reported attitudes, activities and perceptions of students but to assess the effectiveness of instructional activities and the overall course structure. The students' responses to the questionnaire taken online were collected, the number of answers given to each statement was converted to percentages and presented in the table.

\section{$4 \quad$ Results}

The results of the independent-samples t-tests of the achievement scores of both experimental and control groups on the final tests on English language course, Child and Educational Psychology course and Civil law course are given in Table 1, Table 2 and Table 3 correspondingly.

Table 1. Independent-samples t-test results of the achievement scores of the experimental and control groups on the final test (English language course)

\begin{tabular}{|l|c|c|c|c|c|c|}
\hline \multicolumn{1}{|c|}{ Groups } & $\mathbf{N}$ & Mean & SD & Mean Diff & t-value & p-value \\
\cline { 1 - 4 } CG & 20 & 77.63 & 8.10 & 10,83 & -7.502 & $<0,001$ \\
\cline { 1 - 3 } EG & 21 & 88.46 & 6.52 & & & \\
\hline
\end{tabular}

The data shown in Table 1 signify that there is a significant $(p<0,001)$ difference between the achievement of EG and CG on the final test as the calculated t-value is larger than the tabulated t-value at 0.05 . Furthermore, the mean values show that the experimental group $(\mathrm{M}=88.46, \mathrm{SD}=6.52)$ demonstrated more excellent performance as compared to the control group $(\mathrm{M}=77.63, \mathrm{SD}=8.10)$.

Table 2. Independent-samples t-test results of the achievement scores of the experimental and control groups on the final test (Child and Educational Psychology course)

\begin{tabular}{|l|c|c|c|c|c|c|}
\hline \multicolumn{1}{|c|}{ Groups } & N & Mean & SD & Mean Diff & t-value & p-value \\
\hline CG & 26 & 71.73 & 4.18 & 12.78 & -9.747 & $<0,001$ \\
\cline { 1 - 4 } & 26 & 84.52 & 3.21 & & & \\
\hline
\end{tabular}


Table 2 reveals that there was a significant difference $(\mathrm{t}=-9.747, \mathrm{p}<0,001)$ between the experimental group achievement scores $(\mathrm{M}=84.52 ; \mathrm{SD}=3.21)$ and the control group achievement scores $(\mathrm{M}=71.73 ; \mathrm{SD}=4.18)$.

Table 3. Independent-samples t-test results of the achievement scores of the experimental and control groups on the final test (Civil Law course)

\begin{tabular}{|l|c|c|c|c|c|c|}
\hline \multicolumn{1}{|c|}{ Groups } & N & Mean & SD & Mean Diff & t-value & p-value \\
\hline CG & 18 & 74.77 & 5.966 & 10 & -5.582 & $<0,001$ \\
\cline { 1 - 4 } & 18 & 84.77 & 4.71 & & & \\
\hline
\end{tabular}

As it is seen in Table 3, there was a significant difference $(t=-5.582, p<0,001)$ between the experimental group achievement scores $(\mathrm{M}=84,77 ; \mathrm{SD}=4.71)$ and the control group achievement scores $(\mathrm{M}=74.77 ; \mathrm{SD}=5.966)$ in favour of the experimental group.

The comparative results (mean) of the students' academic performance in the English Language course, Child and Education Psychology course and Civil Law course are given in Figure 1.

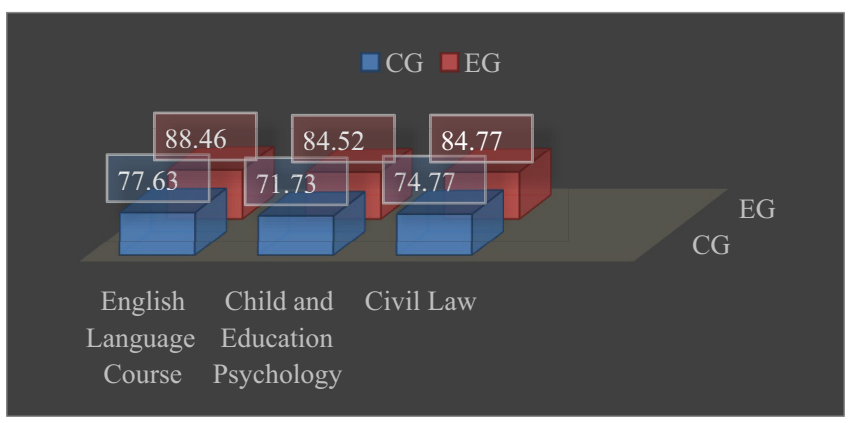

Fig. 1. The comparative analysis of the students' academic performance in English Language course, Child and Education Psychology course and Civil Law course (mean)

Depending on the results achieved, it could be concluded that the described above Seamless Learning Model with Enhanced Web-Quizzing was more effective concerning students' achievement in each course than the traditional teaching methods applied in the control groups. The researchers suggested that the better results of the summative assessment of the experimental group could be attributed to the applied seamless learning approach that presupposed ubiquitous learning, learning in different contexts and with various tasks. Multiple format continuous quizzing could cause testing effect connected with the improved information retrieval and retention and practising self-assessment could be important for self-regulated learning. In addition, when taking the summative test, the students probably experienced a lower level of test anxiety compared with the students of control groups who had not taken regular tests.

The analysis of the answers to Biggs's Revised Two-Factor Study Process Questionnaire (R-SPQ-2F) aimed at evaluating the academic motivation and learners' approaches to the studying process revealed the results shown in Table 4. 
Table 4. Average score and standard deviation on deep and surface approach of the control groups and experimental groups

\begin{tabular}{|c|c|c|c|}
\hline Groups & N & Deep Approach & Surface Approach \\
\hline CGs & 64 & $29.5(5.58)$ & $25.3(6.34)$ \\
\hline EGs & 65 & $36.04(5.47)$ & $22.4(6.17)$ \\
\hline
\end{tabular}

It is seen from Table 4 that both control and experimental groups showed a deep approach towards learning although in the experimental group students achieved a higher deep approach score $(M=36.04)$ than in the control groups $(M=29.5)$ while the surface approach score was higher in the control groups $(\mathrm{M}=25.3)$ in comparison to the experimental groups' score $(M=22.4)$. The number of answers of experimental group students that any topic can be interesting if they once get into it, that they came to most classes with questions in mind that they wanted to answer and that they spend their free time finding out more about interesting topics discussed in different classes can prove the research hypothesis that the intensive use of web quizzing has the potential of changing students' learning strategies and boosting motivation. Students of control groups more often chose the answer "this item is always or almost always true of me" concerning learning by rote or memorizing without understanding.

The questionnaire checking experimental group students' engagement in the web-quizzing enhanced courses revealed the results given in Table 5.

Table 5. The questionnaire results on experimental group students' engagement in the quiz-enhanced courses

\begin{tabular}{|l|c|c|c|c|}
\hline & & & & \\
\end{tabular}


The boosted engagement of experimental group students in the courses with the new methodology is shown in all four aspects checked in the survey: 1) emotional engagement - the majority of students considered the course with the innovative approach interesting, relevant to their personal needs, and reducing their test anxiety (although the percentage of positive answers for this question $(43 \%)$ was higher than negative (34\%), 23\% of students were neutral); 2) skills engagement - students again confirmed the change in their learning strategies revealed in the increase of time they spent on studying and the wish to understand the target information but not just to learn by rote; 3) participation engagement is demonstrated by the increased willingness of $60 \%$ of students to participate in in-class activities and 51\% improving their attendance; 4 ) performance engagement is seen in the recognition that achievements improved throughout the courses $(52 \%)$ and in final tests $(53 \%)$.

\section{$5 \quad$ Discussion and limitation}

The adaptation of seamless learning as a productive solution during the pandemic time and beyond it to continue through the crisis, which provides students with various learning scenarios, resources, media and environments was suggested in various recent research [43]-[45], etc.

The benefits of online testing in educational practice have been researched and analyzed in numerous publications. In our research we are in alignment with the findings of the recent studies conducted by a number of scholars, in particular, we verified the testing effect of enhanced web quizzing leading to improving understanding and active learning [46], [47], studied motivational processes and the role of the immediate feedback in increasing learner engagement and students' positive attitude towards tests [48], [30], [49], [50], estimated a positive effect of online testing on the academic performance and increasing students' achievement [51], [52], witnessed a correlation between the scores obtained on formative tests and the final summative examinations [51], [53].

In the study, the researchers considered contradictory issues connected with online testing raised in previous studies, weighed up both benefits and drawbacks of the phenomenon, took into account all relevant aspects of the issue. The opponents of online testing claim that testing is time-consuming, tedious for students and decreases students' interest in the materials and learning in general [23], provides no fruitful and lifelong learning and focuses only on the information involved in tests [54].

There are some limitations in this study that could be addressed in future research. First, the scope of quizzes in the students' workload, quiz compatibility with other activities, the problem of combating academic dishonesty and plagiarism are worth considering in some depth in prospective studies. Second, the most obvious limitation in this research was the paucity of controlled classroom experiments limited by 129 participants. Taking into account the fact, the results of the study cannot be generalized to all educational communities but transferrable to similar contexts, further research should be done with a larger number of students from different faculties and educational establishments to gain more accurate results. 


\section{Conclusion}

The research shows that the intensive use of web-based quizzes can be an efficient teaching technique for seamless learning able to alter the learning environment making it more innovative and ubiquitous. Carefully created tests have the potential of arising the interest of students in the target material and creating relevance to their personal needs. The shift to more collaborative and at the same time personalized learning observed during the study can help students to develop confidence during the course and reduce test anxiety thus increasing satisfaction and motivation. The researchers suppose that all these factors contribute to the changes in the learners' approaches to studying revealed in students' engagement in in-class and out-of-class activities, mastering of the material through understanding rather than mechanical memorizing, the search for additional information and increased attendance. Online quizzes applied not only as assessing tools but primarily as learning ones focusing on information retrieval and retention showed the testing effect which became obvious in the higher achievements of the experimental group students in the summative tests. Thus, thoroughly designed continuous enhanced testing using diagnostic, formative, benchmark and summative quizzes and applying such features of seamless learning as learning in various contexts, ubiquitous access to digital learning resources and quizzes, combination of teacher-guided learning, self-directed and collaborative learning, and switching between various learning activities may be a powerful learning tool having positive effect on academic performance, motivation, learners' approaches to studying and course engagement especially in pandemic-altered time.

\section{$7 \quad$ References}

[1] Y. Perry, "Cloud computing in education with cloud volumes ONTAP. Cloud central", November 8, 2018. [Online]. Available: https://cloud.netapp.com/blog/cloud-computingin-education-trends-and-challenges

[2] L. Chao (Ed.), "Cloud computing for teaching and learning: Strategies for design and implementation". IGI Global, 2012. Available: https://doi.org/10.4018/978-1-4666-0957-0

[3] S. Palaniappan, "Cloud computing for academic environment," International Journal of Computer Science and Mobile Computing, vol. 5, no. 3, pp. 8-15, 2014.

[4] I. M. Khalil, A. Khreishah, M. Azeem, "Cloud computing security: A survey," Computers, vol. 1, no. 3, pp. 1-35, 2014. [Online]. Available: https://doi.org/10.3390/computers3010001

[5] L. Holubnycha, \& L. Baibekova, "Modern technologies for university students' language learning in pandemic," Postmodern Openings, vol. 2, no. 11, pp. 59-65, 2020. [Online]. Available: https://doi.org/10.18662/po/11.2/158

[6] L.-H. Wong, "A brief history of mobile seamless learning," in seamless learning in the age of mobile connectivity, L.-H. Wong, M. Milrad, \& M. Specht, Eds. Springer, 2015, pp. 3-40. https://doi.org/10.1007/978-981-287-113-8 1

[7] G.D. Kuh, "Guiding principles for creating seamless learning environments for undergraduates," College Student Development, vol. 2, no. 37, pp. 135-148, 1996.

[8] J.C.K. Chan, K.B. McDermott, \& H.L. Roediger, "Retrieval induced facilitation: Initially nontested material can benefit from prior testing of related material," Journal of Experimental Psychology: General, vol. 4, no. 135, pp. 553-571, 2006. Available: https://doi.org/10.1037/ $\underline{0096-3445.135 .4 .553}$ 
[9] L.H. Wong, \& C.-K. Looi, "What seams do we remove in mobile assisted seamless learning? A critical review of the literature," Computers \& Education, vol. 4, no. 57, pp. 2364-2381, 2011. Available: https://doi.org/10.1080/10494820.2012.745424

[10] S. Laisema, \& P. Wannapiroon, "Collaborative learning model with virtual team in ubiquitous learning environment using creative problem solving process," International Journal on Integrating Technology in Education, vol. 4, no. 2, pp. 1-14, 2013. https://doi.org/10.5121/ ijite.2013.2401

[11] T. Paulus, K. Evans, O. Halic, J. Lester, J. Taylor, \& M. Spence, (2009). "Knowledge and learning claims in blog conversations: A discourse analysis in social psychology (DASP) perspective," In Proc. CSCL2009 Conference, C. O’Malley, D. Suthers, P. Reimann \& A. Dimitracopoulou (Eds.), Computer Supported Collaborative Learning Practices, Rhodes, Greece: International Society of the Learning Sciences, 2009, pp. 93-97. https://doi. org/10.3115/1600053.1600067

[12] M. Milrad, L.-H. Wong, M. Sharples, G.-J. Hwang, C.-K. Looi, \& H. Ogata, "Seamless learning: An international perspective on next generation technology enhanced learning," In The Handbook of Mobile Learning, Z.L. Berge \& L.Y. Muilenburg (Eds.), Routledge, 2013, pp. 95-108.

[13] Y. Toh, H.-J. So, P. Seow, W. Chen, \& C.K. Looi, "Seamless learning in the mobile age: A theoretical and methodological discussion on using cooperative inquiry to study digital kids on-the-move," Learning, Media and Technology, vol. 3, no. 38, pp. 301-318, 2013. Available: https://doi.org/10.1080/17439884.2012.666250

[14] C.-K. Looi, L.-H. Wong, \& Y. Song, "Mobile computer supported collaborative learning," In The International Handbook of Collaborative Learning, F. Fischer, C. Hmelo-Silver, S. Goldman, P. Reimann (Eds.), 2018. Available: https://doi.org/10.4324/978131561757

[15] L. Sha, C.-K. Looi, W. Chen, \& B. Zhang, "Understanding mobile learning from the perspective of self-regulated learning," Journal of Computer Assisted Learning, vol. 4, no. 28, pp. 366-378, 2012. https://doi.org/10.1111/j.1365-2729.2011.00461.x

[16] J. Bransford, A. Brown, \& R. Cocking, "How people learn: Brain, mind, and experience \& school," National Academy Press, 2020.

[17] H.L. Roediger III, A.L. Putnam, \& M.A. Smith, "Ten benefits of testing and their applications to educational practice," In Psychology of learning and motivation: Cognition in education, J. Mestre \& B. Ross (Eds.), pp. 1-36, Elsevier, 2011. https://doi.org/10.1016/ B978-0-12-387691-1.00001-6

[18] M.A. McDaniel, J.L. Anderson, M.H. Derbish, \& N. Morrisette, "Testing the testing effect in the classroom," European Journal of Cognitive Psychology, vol. 4-5, no. 19, pp. 494-513, 2007. Available: https://doi.org/10.1080/09541440701326154

[19] J.D. Karpicke, \& H.L. Roediger III, "Repeated retrieval during learning is the key to longterm retention," Journal of Memory and Language, vol. 2, no. 57, pp. 151-162, 2007. Available: https://doi.org/10.1016/j.jml.2006.09.004

[20] S. Hinze, J. Wiley, W. Pellegrino, "The importance of constructive comprehension processes in learning from tests," Journal of Memory and Language, vol. 2, no. 69, pp. 151-164, 2013. Available: https://doi.org/10.1016/j.jml.2013.03.002

[21] T.-W. Chan, J. Roschelle, S. Hsi, A. Kinshuk, M. Sharples, T. Brown, \& U. Hoppe, "Oneto-one technology-enhanced learning: An opportunity for global research collaboration," Research and Practice in Technology-Enhanced Learning, vol. 1, no. 1, pp. 3-29, 2006. Available: https://doi.org/10.1142/S1793206806000032

[22] K.B. Lyle, \& N.A. Crawford, "Retrieving essential material at the end of lectures improves performance on statistics exams," Teaching of Psychology, no. 38, pp. 94-97, 2011. Available: https://doi.org/10.1177/0098628311401587 
[23] H.L. Roediger, \& J.D. Karpicke, "Test-enhanced learning: Taking memory tests improves long-term retention,” Psychological Science, vol. 3, no. 17, pp. 249-255, 2006. Available: https://doi.org/10.1111/j.1467-9280.2006.01693.x

[24] M.A. McDaniel, K.M. Wildman \& J.L. Anderson, "Using quizzes to enhance summativeassessment performance in a web-based class: An experimental study," Journal of Applied Research in Memory and Cognition, vol. 1, no. 1, pp. 18-26, 2012. Available: https://doi. org/10.1016/j.jarmac.2011.10.001

[25] H.L. Roediger, P.K. Agarwal, M.A. McDaniel, \& K.B. McDermott, “Test-enhanced learning in the classroom: Long-term improvements from quizzing," Journal of experimental psychology: applied, vol. 4, no. 17, pp. 382-395, 2011. Available: https://doi.org/10.1037/a0026252

[26] B. Pastötter, J. Weber, \& K. H. Bäuml. "Using testing to improve learning after severe traumatic brain injury," Neuropsychology, vol. 27, no. 2, pp. 280-285, 2013. Available: https:// doi.org/10.1037/a0031797

[27] C. Yang, R. Potts, \& D.R. Shanks. "Enhancing learning and retrieval of new information: A review of the forward testing effect," Science of Learning, vol. 3, no. 8, 2018. Available: https://doi.org/10.1038/s41539-018-0024-y

[28] M.A. McDaniel, P.K. Agarwal, B.J. Huelser, K.M. McDermott, \& H.L. Roediger III, "Test-enhanced learning in a middle school science classroom: The effects of quiz frequency and placement," Journal of Educational Psychology, vol. 2, no. 103, pp. 399-414, 2011. Available: https://doi.org/10.1037/a0021782

[29] A.C. Butler, \& H.L. Roediger III, "Feedback enhances the positive effects and reduces the negative effects of multiple-choice testing," Memory \& Cognition, vol. 3, no. 36, pp. 604-616, 2008. Available: https://doi.org/10.3758/MC.36.3.604

[30] K.K. Szupnar, K.B. McDermott, \& H.L. Roediger III, "Expectation of a final cumulative test enhances long-term retention,” Memory \& Cognition, vol. 5, no. 35, pp. 1007-1013, 2007. Available: https://doi.org/10.3758/BF03193473

[31] K. W. Cho, J. H. Neely, S. Crocco \& D. Vitrano. "Testing enhances both encoding and retrieval for both tested and untested items," Quarterly Journal of Experimental Psychology: Human Experimental Psychology, vol. 70, no. 7, pp. 1-60, 2017. Available: https://doi.org/ 10.1080/17470218.2016.1175485

[32] Z. Schrank, "An assessment of student perceptions and responses to frequent low-stakes testing in introductory sociology classes," Teaching Sociology, vol. 44, no. 2, pp. 118 -127, 2016. Available: https://doi.org/10.1177/0092055X15624745

[33] C. E. Heiner, A. I. Banet, \& C. Wieman. "Preparing students for class: How to get $80 \%$ of students reading the textbook before class," American Journal of Physics, vol. 82, no. 10, pp. 989 -996, 2014. Available: https://doi.org/10.1119/1.4895008

[34] S. Ainsworth, \& A.T. Loizou, "The effects of self-explaining when learning with texts or diagrams," Cognitive Science, no. 27, pp. 669-681, 2003. Available: https://doi.org/10.1207/ $\underline{\mathrm{s} 15516709 \operatorname{cog} 2704 \_5}$

[35] J.F. McNamara, (2004) "Getting good results from survey research: Part III", International Journal of Educational Reform, vol. 4, no. 13, pp. 356-373, 2004. Available: https://doi. org $/ 10.1177 / 105678790401300404$

[36] N.J. Cepeda, H. Pashler, E. Vul, J.T. Wixted, \& D. Rohrer, "Distributed practice in verbal recall tasks: A review and quantitative synthesis," Psychological Bulletin, vol. 3, no. 132, pp. 354-380, 2006. Available: https://doi.org/10.1037/0033-2909.132.3.354

[37] J.D. Karpicke, A.C. Butler, \& H.L. Roediger III, "Metacognitive strategies in student learning: Do students practise retrieval when they study on their own?" Memory, vol. 4, no. 17, pp. 471-479, 2009. Available: https://doi.org/10.1080/09658210802647009 
[38] J. C. Chan, K.D. Manley, S.D. Davis, \& K.K. Szpunar. "Testing potentiates new learning across a retention interval and a lag: A strategy change perspective," Journal of Memory and Language, vol. 102, pp. 83-96, 2018. Available: https://doi.org/10.1016/j.jml.2018.05.007

[39] J.B. Biggs, D. Kember, \& D.Y.P. Leung, "The revised two factor study process questionnaire: R-SPQ-2F,” British Journal of Educational Psychology, vol. 1, no. 71, pp. 133-149, 2001. Available: https://doi.org/10.1348/000709901158433

[40] PSC Goh, "Perceptions of learning environments, learning approaches, and learning outcomes: A Study of private higher education students in Malaysia from twinning programmes," Adelaide: University of Adelaide, 2005.

[41] Z.S. Siddiqui, "Study approaches of students in Pakistan: The revised two-factor study process questionnaire experience," In Proc. Conference on Teaching and Learning in Higher Education, 2006, Pakistan National Academy of Higher Education.

[42] M.M. Handelsman, W.L. Briggs, N. Sullivan, \& A. Towler, "A measure of college student course engagement", The Journal of Educational Research, vol. 3, no. 98, pp. 184-191, 2005. Available: https://doi.org/10.3200/JOER.98.3.184-192

[43] A. Keener, "Delivering a seamless digital experience beyond the pandemic," The Evollution, 2020. Available: https://evolllution.com/managing-institution/operations efficiency/ delivering-a-seamless-digital-experience-beyond-the-pandemic/

[44] K. Suartama, P. Setyosari, S. Sulthoni, S. Ulfa, "Development of ubiquitous learning environment based on moodle learning management system", International Journal of Interactive Mobile Technologies, vol. 14, no. 14, pp. 182-204, 2020. Available: https://doi.org/ 10.3991/ijim.v14i14.11775

[45] P.J. Arul Leena Rose, \& T. Ananthi Claral Mary, "Accelerating the move towards online learning through cloud platforms in higher education sectors using smart devices during COVID-19”, International Journal of Interactive Mobile Technologies, vol. 15, no. 10, pp. 16-32, 2021. Available: https://doi.org/10.3991/ijim.v15i10.22163

[46] V. Halamish, \& R.A. Bjork, "When does testing enhance retention? A distribution-based interpretation of retrieval as a memory modifier," Journal of Experimental Psychology: Learning, Memory, and Cognition, vol. 4, no. 37, pp. 801-812, 2011. Available: https://doi. org/10.1037/a0023219

[47] M. Ong, N. Yasin, N. Ibrahim, "Immersive experience during Covid-19: The mediator role of alternative assessment in online learning environment", International Journal of Interactive Mobile Technologies, vol. 15, no. 18, pp. 16-32, 2021. Available: https://doi.org/10.3991/ ijim.v15i18.24541

[48] H.L. Roediger, \& E.J. Marsh, "The positive and negative consequences of multiple-choice testing," Journal of Experimental Psychology: Learning, Memory, and Cognition, vol. 5, no. 31, pp. 1155-1159, 2005.

[49] D. Cohen, I. Sasson, "Online quizzes in a virtual learning environment as a tool for formative assessment," Journal of Technology and Science Education, vol. 3, no. 6, pp. 188-208, 2016. Available: http://dx.doi.org/10.3926/jotse.217

[50] R. Wallihan, K.G. Smith, M.D. Hormann, R.R. Donthi, K. Boland, \& J.D. Mahan, "Utility of intermittent online quizzes as an early warning for residents at risk of failing the pediatric board certification examination," Report, BMC Medical Education, vol. 1, no. 18, 2018. Available: https://doi.org/10.1186/s12909-018-1366-0

[51] M. Galizzi, (2010). "An assessment of the impact of online quizzes and textbook resources on students' learning," International Review of Economic Education, Economics Network, vol. 1, no. 9, pp. 31-43, 2010. Available: https://doi.org/10.1016/S1477-3880(15)30062-1

[52] M.J. Brown, \& J.A. Tallon, "The effects of pre-lecture quizzes on test anxiety and performance in a statistics course," Education, 2015, pp. 3-13, 135, 346-350. 
[53] A.C. Butler, \& H.L. Roediger III, (2007). "Testing improves long-term retention in a simulated classroom setting," European Journal of Cognitive Psychology, vol. 4-5, no. 19, pp. 514-527, 2007. Available: https://doi.org/10.1080/09541440701326097

[54] B. Marshall, "Testing english. Formative and summative approaches to english assessment," Continuum, 2011.

\section{Authors}

Svitlana Mykytiuk is PhD in Philology, Associate Professor, Department of Foreign languages \# 1, Yaroslav Mudryi National Law University, Kharkiv, Ukraine. The research interests are innovative methods of teaching foreign languages, technology assisted learning and comparative study of literature. (s.s.mykytyuk@nlu.edu.ua)

Tetiana Moroz is PhD in Philology, Associate Professor, Department of Foreign languages \# 1, Yaroslav Mudryi National Law University, Kharkiv, Ukraine. The research interests are methods of teaching foreign languages, technology-enhanced language learning, and linguistic studies. (t.yu.moroz@,nlu.edu.ua)

Serhii Mykytiuk is Doctor of Pedagogical Sciences, PhD in Psychology, Full Professor, Department of Philosophical and Psychological Anthropology, H. S. Skovoroda Kharkiv National Pedagogical University, Kharkiv, Ukraine. The research interests are educational psychology, developmental psychology, social psychology, and interactive teaching methods. (s.mykytiuk@hnpu.edu.ua)

Mykola Moroz is PhD in Law, Associate Professor, Department of Civil Law \# 2, Yaroslav Mudryi National Law University, Kharkiv, Ukraine. The research interests are standards of legal education, modern legal education toolkit, enhanced academic integrity in law, and Civil law. (m.v.moroz@nlu.edu.ua)

Olga Dolgusheva is $\mathrm{PhD}$ in Philology, Associate Professor, Department of Germanic Languages and Teaching Methodology, Volodymyr Vynnychenko Central Ukrainian State Pedagogical University, Kropyvnytskyi, Ukraine. The research interests are Linguistics, EFL, teaching methodology. (‥V.Dolhusheva@cuspu.edu)

Article submitted 2021-10-03. Resubmitted 2021-11-15. Final acceptance 2021-11-15. Final version published as submitted by the authors. 